\title{
Evaluation of Bactericidal Action of Serum Collected from Paratyphoid Patients and Normal Human against Salmonella Paratyphi
}

\section{Md. Chhanaur Rabbee, Mohammad Shahriar, Mohiuddin Ahmed Bhuyian, Rishikesh and Md. Asraful Islam}

\author{
Microbiology and Biotechnology Research Laboratory, Department of Pharmacy, \\ University of Asia Pacific, Dhanmondi, Dhaka-1209, Bangladesh
}

\begin{abstract}
A comparative study of susceptibility of clinical isolates of Salmonella Paratyphi to bactericidal action of S. Paratyphi infected human serum and uninfected human serum was investigated. Bactericidal action of $S$. Paratyphi infected human serum and uninfected human serum was assessed after incubating the bacterial suspension of $S$. Paratyphi with $40 \%$ of both infected and unifected human serum at various incubation times. Eight samples of $S$. Paratyphi infected serum from the patients diagnosed with paratyphoid fever were used. The investigation found that the serum killed $S$. Paratyphi both by classical and alternative pathways. Anti- $S$. Paratyphi antibodies for the bactericidal action of serum were examined by the assessment of bactericidal activity of non-immune normal human serum. Significant killing of $S$. Paratyphi by $S$. Paratyphi infected serum was investigated and the serum mediated killing was increased by increasing the incubation time. The mean growth declines gradually as the incubation time was increased. No noteworthy serum mediated killing was observed for normal human serum and inactivated (heat induced) S. Paratyphi infected serum.
\end{abstract}

Key words: Salmonella Paratyphi, bacteriocidal, serum, paratyphoid.

\section{INTRODUCTION}

Salmonella Typhi caused an estimated 22 million illnesses and 200,000 deaths, and S. Paratyphi caused 5.4 million illnesses worldwide in $2000 .{ }^{1}$ The actual global burden of enteric fever is difficult to determine because many cases are unrecognized, particularly in young children who may have a nonspecific illness ${ }^{2}$ and it is not a notifiable disease in endemic countries. With an estimated 16-33 million cases of typhoid fever annually resulting in 500,000 to 600,000 deaths in endemic areas, the World Health Organization identifies typhoid, caused by the bacterium Salmonella enterica serovar Typhi as a serious public health problem. Its incidence is the highest in children and young adults between 5 and 19 years old. Susceptibility to the serum bactericidal system is a

Correspondence to: Mohiuddin Ahmed Bhuyian

Tel: +88-02-8629367, +88-01711172189

E-mail: mohiuddin@uap-bd.edu

Dhaka Univ. J. Pharm. Sci. 12(1): 71-75, 2013 (June) widespread characteristic of gram-negative bacteria. In addition to the many well-documented instances of enterobacterial susceptibility to complement, serum is known to possess bactericidal and bacteriolytic activity against susceptible representatives of practically every gram-negative genus so far examined. ${ }^{3}$

The bactericidal effect of normal human serum plays an important role in host defense against bacterial infection. This phenomenon has been widely noted and studied since the late $1800 \mathrm{~s}^{3}$ and has been shown to be complement mediated. ${ }^{4,5}$ Early colonization of the intestinal tract by commensally bacteria ensures that small quantities of antibodies directed against the surface antigens of many types of gram-negative bacteria are present in the blood and tissue fluids of humans ${ }^{6}$ and a variety of animals. Thus, IgM and IgG antibodies directed against surface antigens of $E$. coli $^{8}$ and other enterobacteria ${ }^{9}$ as well as against Neisseria species. ${ }^{8,10}$ However, the development of the humoral immune response to $\mathrm{O}, \mathrm{H}$, 
and $\mathrm{Vi}$ antigens of $S$. Typhi has been regularly demonstrated during and after typhoid fever. ${ }^{11}$ As a result, the sera of typhoid fever patients had been shown to harbor antibodies against $\mathrm{O}, \mathrm{H}$, and $\mathrm{Vi}$ antigens. ${ }^{12-14}$ Therefore, sera from patient diagnosed with typhoid can provide the source for anti- $S$. Typhi antibodies, along with the proteins of complement system. $^{15}$

Numerous studies show killing of gram-negative bacteria is mediated by the antibody- complement system. ${ }^{3-5}$ The requirement of the anti- $S$. Typhi antibodies and the consequent activation of classical activation were investigated by examining the bactericidal activity of normal human sera, depriving of anti- $S$. Typhi antibodies, against $S$. Typhi. In the present study, bactericidal activity of $S$. Paratyphi infected human serum against $S$. Paratyphi was investigated which provided the source for anti- $S$. Paratyphi antibodies and complement pathways previously showed to be required by the many investigators for the serum mediated killing of $S$. Paratyphi. ${ }^{5,16}$ In present study, the requirement for complement pathways in serum mediated killing of $S$. Paratyphi is also examined by means of inactivating both classical and alternative pathways of $S$. Paratyphi infected human sera. The requirement of the anti- $S$. Paratyphi antibodies and the consequent activation of classical activation were investigated by examining the bactericidal activity of normal human sera, depriving of anti- S. Paratyphi antibodies, against S. Paratyphi.

\section{MATERIALS AND METHOD}

Bacterial strain and inoculums preparation. The S. paratyphi bacterial strain was collected from the microbiology department of Medinova Medical Services Ltd., Dhaka, Bangladesh. The bacterial strain was collected as red colony with black centre on a Xylose Lysine Deoxycholate (XLD) agar plate and was tested using gram staining, and other serological study. The organism was maintained at $-20^{\circ} \mathrm{C}$ through stock preparation for further use. Stock culture was streaked on a XLD plate and incubated at $37^{\circ} \mathrm{C}$ overnight. S. paratyphi from the overnight subculture was then transferred into $100 \mathrm{ml}$ of normal saline, shaken to break the clumps and then adjusted to desired concentration by serial dilution.

Collection of normal human sera. Blood from eight healthy volunteer with proper medical history were collected aseptically by venipuncture. Blood were kept still in test tubes at $4^{\circ} \mathrm{C}$ overnight, centrifuged at $2000 \mathrm{x}$ g for $30 \mathrm{~min}$. The sera were separated and stored at $-20^{\circ} \mathrm{C}$ in small aliquots until used.

Collection of $S$. paratyphi infected human sera. Sera from eight $S$. paratyphi infected patients who were diagnosed with paratyphoid fever were collected from Bangabandhu Sheikh Mujib Medical University, Dhaka, Bangladesh. The sera were stored at $-20^{\circ \mathrm{C}}$ in small aliquots until used.

Serum bactericidal assay. The serum bactericidal assay for all eight $S$. Paratyphi infected human sera and eight normal human sera were carried out. Bacterial cell suspension of $4.48 \log _{10} \mathrm{CFU} / \mathrm{ml}$ was treated with $40 \%$ human serum (this was found to be the optimum concentration) and incubated at $37^{\circ} \mathrm{C}$ for different periods of time. The treated bacterial suspension was then spread on nutrient agar plate (stored at $4^{\circ} \mathrm{C}$ for 2 days before use). After 24 hours of incubation of bacterial suspension on nutrient plate at $37^{\circ} \mathrm{C}$, the growth of $S$. Paratyphi (CFU) was counted. Bacterial cell suspension of $4.48 \log _{10} \mathrm{CFU} / \mathrm{ml}$ diluted with $40 \%$ normal saline served as positive control. 60 $\mu \mathrm{l}$ bacterial cell suspension $\left(4.48 \log _{10} \mathrm{CFU} / \mathrm{ml}\right)$ was added to $40 \mu \mathrm{l}$ physiological saline which was used as positive control. $60 \mu \mathrm{l}$ physiological saline was added to $40 \mu \mathrm{l}$ serum which was used as negative control.

Treatment of sera. Exposure of many strains of gram-negative bacteria to suitable concentrations of human or animal serum results in loss of viability, and sometimes dissolution of the bacterial cells. Since the recognition, towards the end of the last century, that the bactericidal and bacteriolytic properties of serum are destroyed by heating at $56^{\circ} \mathrm{C}$, an extensive literature has accumulated indicating that the killing process is affected by deposition on or insertion into the bacterial envelope of the assembled terminal proteins of the complement cascade, the membrane 
attack complex (MAC). It is now clear that activation of complement by gram-negative bacteria can occur via the classical or the alternative pathway; the former usually requires, for its activation, recognition of bacterial surface antigens by certain antibody classes, whereas activation of the latter can be initiated and amplified, in the absence of antigen-antibody interactions, by poorly understood structural or conformational characteristics of the cell surface. Killing by serum is often, but not invariably, accompanied by bacteriolysis, an event dependent on adequate amounts of lysozyme (mucopeptide $\mathrm{N}$ acetylmuramoylhydrolase EC 3.2.1.17); this basic enzyme degrades peptidoglycan to form monomers or multiples of the disaccharide-tetra-peptide unit $^{3}$, because of this the eight $S$. Paratyphi infected sera were inactivated by heating at $56^{\circ} \mathrm{C}$ for $30 \mathrm{~min}$. After the heat treatment, the sera were subjected to serum bactericidal assay. ${ }^{17}$

\section{RESULTS}

Serum bactericidal assay. The mean of the CFU of $S$. Paratyphi observed at various incubation times in per $\mathrm{ml}$ of bacterial cell suspension treated with each of eight $S$. Paratyphi infected human sera, eight normal human sera, and eight heat-treated S. Paratyphi infected human sera was calculated. Mean growth of bacterial suspension treated with each of eight $S$. Paratyphi infected human sera, eight normal human sera, and eight heat-treated $S$. Paratyphi infected human sera were plotted against various incubation times (Figure 1).

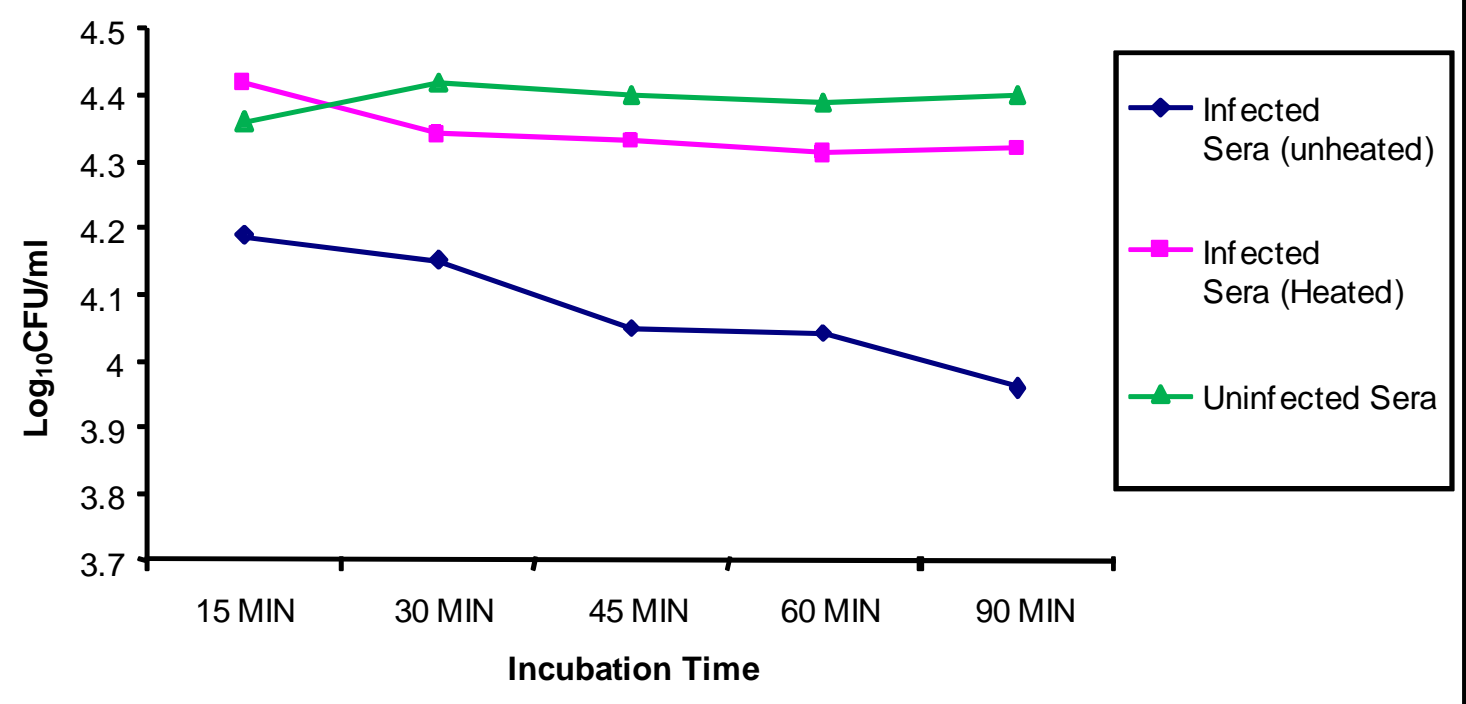

Figure 1. Mean bactericidal activity ( $\left.\log _{10} \mathrm{CFU} / \mathrm{ml}\right)$ of $S$. Paratyphi infected sera (Unheated), S. Paratyphi infected sera (Heated) and Normal human sera.

Serum bactericidal assay for normal human

Sera. The upper limit of $\mathrm{X}$-axis indicates the positive control $4.48 \log _{10} \mathrm{CFU} / \mathrm{ml}$ in Figure 1. The mean growth for normal human sera treated bacterial suspension observed just below line of positive control, no significant change in mean growth is observed at various incubation times.
Serum bactericidal assay for $S$. paratyphi infected human sera. The mean growth for $S$. Paratyphi infected human sera treated bacterial suspension shows apparent decline than the control at various incubation time. The mean growth slides down gradually as the incubation time is increased with sharp decrease observed when incubation time is increased from 60 mins to 90 mins (Figure 1). 
Serum bactericidal assay for heat treated $S$. paratyphi infected human sera. The mean growth for heat-treated $S$. Paratyphi infected human sera treated bacterial suspension is observed at somewhat lower range than the mean growth for normal human serum treated (Figure 1).

\section{DISCUSSION}

Exposure of many strains of gram-negative bacteria to suitable concentrations of human or animal serum results in loss of viability, and sometimes dissolution, of the bacterial cells. ${ }^{3}$ Numerous studies show killing of gram-negative bacteria is mediated by the antibody-complement system. ${ }^{16}$ It is now clear that activation of complement by gram-negative bacteria can occur via the classical or the alternative pathway; the former usually requires for its activation recognition of bacterial surface antigens by certain antibody classes, whereas activation of the latter can be initiated by insoluble immune complexes, but this mode of initiation is likely to be of only minor importance in serum bactericidal reactions. ${ }^{3}$ Serum bactericidal activity against $S$. Paratyphi requires the presence of anti- $S$. Paratyphi antibodies for classical pathway activation and subsequent killing by membrane attack complex (MAC) formation. ${ }^{3}$ Furthermore, antibodies against some overtly pathogenic gram- negative bacteria, such as Vibrio cholerae and S. Paratyphi, are generally absent from non-immune sera. ${ }^{3}$ However, the sera of paratyphoid fever patients, mark the existence of antibodies against $\mathrm{H}$, and Vi antigens as a result of humoral immune response. ${ }^{12}$ Therefore, serum from humans diagnosed with paratyphoid fever are used in the present study is used as the source for complement system and antibodies against $S$. Paratyphi.

Bactericidal activity of eight $S$. Paratyphi infected human sera was examined against clinical isolate of $S$. Paratyphi. The strain was highly susceptible to serum mediated killing by each of the eight $S$. Paratyphi infected human sera as evident by grand reduction in CFU in the growth of bacterial suspension with comparison to the positive control. These incidence marks the killing of $S$. Paratyphi by complement system and anti- $S$. Paratyphi antibodies. Furthermore, as the incubation time is increased, more intense serum bactericidal activity was observed, indicating that up to 90 min serum bactericidal activity can be enhanced by increasing the exposure time of the bacterial suspension to the serum.

The present study showed that the mean bactericidal activity of $S$. Paratyphi infected unheated sera is gradually decreasing. And the mean bactericidal activity of $S$. Paratyphi infected heated human sera is also gradually decreasing at 15 mins of incubation time to 90 mins of incubation time. Bactericidal activity of normal human sera is gradually increasing and the mean bacterial growth declines at 15 mins of incubation time to 90 mins of incubation time. In present study, the requirement for complement pathways in serum mediated killing of $S$. Paratyphi is also examined by means of inactivating both classical and alternative pathways by heating each of the eight S. Paratyphi infected human sera at $56^{\circ} \mathrm{C}$ for $30 \mathrm{~min}^{3}$ before exposing the bacterial suspension to the sera. This practice resulted in almost all if not complete loss of serum bactericidal activity. Therefore, provided the evidence of the requirement of complement system pathways in serum mediated killing of $S$. Paratyphi. The requirement of the anti- $S$. Paratyphi antibodies and the consequent activation of classical activation was investigated by examining the bactericidal activity of eight normal human sera, depriving of anti $S$. Paratyphi antibodies, against $S$. Paratyphi. This study was unable to show any considerable killing of bacterial cell suspension, signifying the necessity of anti- $S$. Paratyphi antibodies in the serum for classical pathway activation and subsequent killing by MAC formation.

\section{REFERENCES}

1. Crump, J. A., Luby, S. P. and Mintz, E. D. (2004). The Global burden of typhoid fever. Bull. World Health Organ. 82, 346-353.

2. Ferreccio, C., Morris, J.G. and Valdivieso, C. 1988. Efficacy of ciprofloxacin in the treatment of chronic typhoid carriers. $J$. Infectious Diseases 157, 1235-1239.

3. Taylor, P.W. 1983. Bactericidal and bacteriolytic activity of serum against gram-negative bacteria. Microbiol. Mol. Biol. Rev. 47, 46-83. 
4. Inoue, K., Yonemasu, K., Takamizawa, A. and Amano, T. 1968. Studies on the immune bacteriolysis. XIV. Requirement of all nine components of complement for immune bacteriolysis. Biken. J. 11, 203-206.

5. Sansano, M. Jr., Reynard, A. M. and Cunningham, R. K. 1985. Inhibition of serum bactericidal reaction by lipopolysaccharide. Infec. Immun. 48, 759-762.

6. Mason, T.G. and Richardson, G. 1981. Escherichia coli and the human gut: some ecological considerations. J. Appl. Bacteriol. 1, 1-16.

7. Sterzl, J., Kostka, J. and Lanc, A. 1962. Development of bactericidal properties against gram-negative organisms in the serum of young animals. Folia Microbiol (Prague). 72, 162-174.

8. Cohen, I.R. and Norins, L.C. 1966. Natural human antibodies to gram-negative bacteria: immunoglobulins $\mathrm{G}, \mathrm{A}$, and $\mathrm{M}$. Science 152, 1257-1259.

9. Michael, J.G. and Rosen, F.S. 1963. Association of "natural" antibodies to gram-negative bacteria with the $\mathrm{Xl}$ macroglobulius. J. Exp. Med. 118, 619-626.

10. Goldkchneider, I., Gotschlich, E.C. and Artenstein, M.S. 1969. Human immunity to the meningococcus. II. Development of natural immunity. J. Exp. Med. 129, 13271348.

11. Kumar, R., Malaviya, A. N., Murthy, R. G., Venkataraman, M. and Mohapatra, L. N. 1974. Immunological Study of Typhoid: Immunoglobulins, C3, Antibodies, and Leukocyte Migration Inhibition in Patients with Typhoid Fever and TAB-Vaccinated Individuals. Infect. Immun. 10, 1219-1225.
12. Hornick, R.B., Greisman, S.E., Woodward, T.E., Dupont, H.L., Dawkins, A.T. and Snyder, M.J. 1970. Typhoid fever, pathogenesis and immunological control, parts 1 and 2. $N$. Engl. J. Med. 283, 686-691, 739-746.

13. Rajagopalan, P., Kumar, R. and Malaviya, N. 1981. Immunological studies in typhoid fever. 1. Immunoglobulins, C3, antibodies, rheumatoid factor and circulating immune complexes in patients with typhoid fever. Clin. Exp. Immunol. 44, 68-73.

14. Ortiz, V., Isibasi, A., García-Ortigoza, E. and Kumate, J. 1989. Immunoblot detection of class-specific humoral immune response to outer membrane proteins isolated from Salmonella typhi in humans with typhoid fever. J. Clin. Microbiol. 27, 1640-1645.

15. Buchner, H. 1889. Uber die bakterientotende Wirkung des zellenfreien Blutserums. Zentralbl Bakt Parasitenkd Infektionskr Hyg Erste Abt Orig Reihe A Med Mikrobiol Parasitol. 5, 817-823.

16. Schwab, G.E. and Reeves, P.R. 1996. Comparison of the bactericidal activity of different vertebrate sera. J. Bacteriol. 91, 106-112.

17. Shahriar, M., Halder, L.D., Nushrat, N., Hossain, M., Kabir, A.N.M.H. and Kabir, S. 2010. Comparison of Bactericidal Activity of Serum Collected from Typhoid Patients and Normal Human Against Salmonella Typhi at Various Incubation Time. Dhaka Uni. J. Pharm. Sci. 9, 65-67. 